\title{
Fabrication of composite positive electrode sheet with high active material content and effect of fabrication pressure for all-solid-state battery
}

\author{
Mari YAMAMOTO ${ }^{\dagger}$, Masanari TAKAHASHI, Yoshihiro TERAUCHI, \\ Yasuyuki KOBAYASHI, Shingo IKEDA and Atsushi SAKUDA* \\ Osaka Municipal Technical Research Institute, 1-6-50 Morinomiya, Joto-ku, Osaka 536-8553, Japan \\ ${ }^{*}$ Research Institute of Electrochemical Energy, Department of Energy and Environment, National Institute \\ of Advanced Industrial Science and Technology, 1-8-31 Midorigaoka, Ikeda, Osaka 563-8577, Japan
}

The development of a fabrication process for sheet-type all-solid-state batteries with high energy density is critical for industrial applications. In this study, we systematically investigate the fabrication process of cells using composite positive electrode sheets with a high ratio of active materials. $n$-Decane was selected as a suitable solvent for the slurry because it has a sufficiently low vapor pressure and does not affect the ionic conductivity of solid electrolytes. In addition, the pre-densification of the composite positive electrode sheets was found to be effective in improving the cell performance. Suitable fabrication pressures were also determined. The cells fabricated under low-pressure conditions exhibited higher discharge capacities despite the higher internal resistance. Finally, our study revealed that the fracturing of $\mathrm{LiNi}_{1 / 3} \mathrm{Co}_{1 / 3} \mathrm{Mn}_{1 / 3} \mathrm{O}_{2}(\mathrm{NCM})$ occurs under high-pressure fabrication conditions because of the compression between the closely located NCM particles, resulting in the cleavage of the ionic and electronic conduction pathways.

(C2017 The Ceramic Society of Japan. All rights reserved.

Key-words : Sheet-type all-solid-state battery, Composite positive electrode sheet, Slurry coating method, Fabrication pressure, High ratio of active materials

[Received December 22, 2016; Accepted February 15, 2017]

\section{Introduction}

All-solid-state lithium-ion batteries using inorganic solid electrolytes (instead of organic liquid electrolytes) have been developed for realizing high power/energy density, long battery life, and high safety/reliability. ${ }^{1)}$ The all-solid-state batteries using oxide-based solid electrolytes, which are expected to be the safest battery system, can operate in the form of thin-film batteries with thicknesses of $10 \mu \mathrm{m} .{ }^{2)}$ However, it is difficult to increase the electrode thickness, which effectively increased the battery capacity, for these batteries because of the high grain boundary resistance of the solid electrolyte in the present stage. In contrast, sulfide-based solid electrolytes, such as $\mathrm{Li}_{3.25} \mathrm{Ge}_{0.25} \mathrm{P}_{0.75} \mathrm{~S}_{4}$ (thioLISICON), ${ }^{3)}$ and $\mathrm{Li}_{2} \mathrm{~S}-\mathrm{P}_{2} \mathrm{~S}_{5},{ }^{4-6)}$ exhibit high lithium ionic conductivity. In addition, the grain boundary resistance is not a dominant resistance component in the compressed pellets of $\mathrm{Li}_{2} \mathrm{~S}_{-} \mathrm{P}_{2} \mathrm{~S}_{5}$ at room temperature. ${ }^{7)}$ Therefore, all-solid-state batteries using sulfide-based solid electrolytes can operate as bulk-type batteries, which can be used for application in automobiles and large stationary storage batteries with large capacities in the future.

The bulk-type batteries can be classified as pellet-type batteries and sheet-type batteries. Most sulfide-based all-solid-state batteries are pellet-type batteries and have been reported to exhibit high cycle performance. ${ }^{8), 9)}$ For instance, pellet-type batteries with a composite positive electrode prepared by dry-mixing $\mathrm{LiCoO}_{2}, \mathrm{Li}_{2} \mathrm{~S}-\mathrm{P}_{2} \mathrm{~S}_{5}$, and acetylene black with a weight ratio of 40:60:6 were reported to have been charged and discharged for more than 500 cycles while retaining a high capacity of approx-

\footnotetext{
Corresponding author: M. Yamamoto; E-mail: mari@omtri.or.jp
}

imately $100 \mathrm{mAh} \mathrm{g}^{-1}$. $^{10)}$ However, for a majority of studies on pellet-type batteries, the ratios of active material content in the electrode composite have been found to be relatively low, in the range of $40-70 \mathrm{wt} \%$, because it is difficult to uniformly disperse the active materials and solid electrolyte by dry-mixing using an agate mortar and pestle. Therefore, to maximize the capabilities of the active materials, the ratios of the active material content in the composite electrode should be decreased for the cell test. In addition, it is generally assumed that cells fabricated under high compression pressure, such as $360 \mathrm{MPa}$, exhibit improved cell performance because the ionic conductivity of sulfide-based solid electrolyte pellets increases with increasing pressure owing to the reduction in the interface resistance between the solid electrolyte particles. ${ }^{11)}$

Sheet-type batteries are suitable for industrial-scale processing because the productivity of the cells and the sheet area can be easily increased for practical applications. However, studies on the fabrication process of sheet-type batteries using sulfide-based solid electrolytes are limited. ${ }^{12), 13)}$

In this study, we investigated the fabrication process of composite positive electrode sheets using a slurry-coating method. To increase the energy density of the cells, the ratio of the active material content in the composite positive electrode was increased to more than $80 \mathrm{wt} \%$. Considering that organic liquid electrolytes can easily form an effective electrode-electrolyte interface by soaking the electrode in the liquid electrolyte, fine solid electrolyte particles with diameters of approximately $1 \mu \mathrm{m}$ were used in the composite electrode to increase the contact area between the active materials and solid electrolyte. ${ }^{14), 15)}$ To prepare a homogeneously dispersed slurry with a high ratio of active 
material content, mechanical mixing was performed using a planetary mixer and ultrasonic homogenizer. We also selected $n$-decane for the slurry with a suitable vapor pressure that did not affect the ionic conductivity of the solid electrolyte. Finally, we investigated the effect of the compression pressure used to prepare the composite positive electrode sheets and cells on the charge-discharge capacity and internal resistance of batteries.

\section{Experimental procedures}

All the process-related experiments, including the material synthesis, slurry coating, and cell fabrication, were conducted in a dry-argon environment. $75 \mathrm{Li}_{2} \mathrm{~S} \cdot 25 \mathrm{P}_{2} \mathrm{~S}_{5}(\mathrm{~mol} \%)$ glass $\left(\mathrm{Li}_{3} \mathrm{PS}_{4}\right.$ glass), abbreviated as LPS, was selected as the solid electrolyte. ${ }^{5 \text { ) }}$ The LPS was prepared from a mechanical milling reagent-grade $\mathrm{Li}_{2} \mathrm{~S}$ (Furuuchi Chemical, 99.9\%) and $\mathrm{P}_{2} \mathrm{~S}_{5}$ (Sigma-Aldrich, 99\%) using a high-energy planetary ball mill (Pulverisette 7, Fritsch). $\mathrm{Li}_{2} \mathrm{~S}(30 \mathrm{mmol})$ and $\mathrm{P}_{2} \mathrm{~S}_{5}(10 \mathrm{mmol})$ with a molar ratio of $75: 25$ were dry-mixed using an agate mortar for $10 \mathrm{~min}$. The mixture was added to a zirconia pot $(80 \mathrm{ml})$ with zirconia balls $(5 \mathrm{~mm}$ in diameter, $106 \mathrm{~g}$ ) and $8 \mathrm{~g}$ of heptane and mechanically milled under a rotating speed of $500 \mathrm{rpm}$ for $20 \mathrm{~h}$ at room temperature. The fine LPS powder (approximately $1 \mu \mathrm{m}$ in diameter) used as the basis for the cells was prepared by pulverizing the as-prepared LPS (approximately $10 \mu \mathrm{m}$ in diameter, $1 \mathrm{~g}$ ) in heptane $(8.9 \mathrm{~g})$ and butyl ether $(0.2 \mathrm{~g})$ with zirconia balls $(1 \mathrm{~mm}$ in diameter, $40 \mathrm{~g})$ under a rotating speed of $200 \mathrm{rpm}$ for $20 \mathrm{~h}^{14}$ )

The effect of the solvent on the LPS was investigated as follows. LPS $(100 \mathrm{mg})$ and the solvent $(0.5 \mathrm{ml})$ were mixed for one day and then dried at room temperature for two days. The ionic conductivities of the resulting products were measured for the pellets $(80 \mathrm{mg})$ under $333 \mathrm{MPa}$ using a $\mathrm{Li}^{+}$ion blocking cell (SUS/LPS/SUS) and an impedance analyzer (FRA1455, Solartron) in the frequency range of $0.1 \mathrm{~Hz}$ to $1 \mathrm{MHz}$ at room temperature.

Commercially available $\mathrm{LiNi}_{1 / 3} \mathrm{Co}_{1 / 3} \mathrm{Mn}_{1 / 3} \mathrm{O}_{2}$ (NCM), approximately $5 \mu \mathrm{m}$ in diameter, was coated with the oxide to effectively produce a low-resistance interface between the active materials and $\mathrm{Li}_{2} \mathrm{~S}-\mathrm{P}_{2} \mathrm{~S}_{5}$ glass. ${ }^{16), 17)}$ Thus, NCM coated with $\mathrm{LiNbO}_{3}{ }^{16)}$ was used as the active material. The solid components in the slurry were $\mathrm{LiNbO}_{3}$-coated $\mathrm{NCM}$, fine LPS, acetylene black (AB), and styrene-ethylene-butylene-styrene (SEBS) binder with a weight ratio of $80: 20: 2: 1$. The mixture was dispersed in $n$-decane, toluene, or 1,2-dichloroethane as solvents, using a planetary mixer (Mazerustar KK-250S, Kurabo) at $1600 \mathrm{rpm}$ for $3 \mathrm{~min}$ and ultrasonic irradiation for $1 \mathrm{~min}$ using an ultrasonic homogenizer (UP100H, Hielscher). The slurry was coated onto aluminum foil (thickness $=20 \mu \mathrm{m})$ using an applicator $(\mathrm{gap}=200 \mu \mathrm{m})$ and then dried at room temperature for $24 \mathrm{~h}$. The composite positive electrode sheets were cut into circles with diameters of $9.5 \mathrm{~mm}$ and compressed under pressures of 3,18, and $37 \mathrm{MPa}$.

All-solid-state cells were fabricated as follows. The composite positive electrode sheets previously compressed under $37 \mathrm{MPa}$ pressure along with fine LPS powder $(80 \mathrm{mg})$ were pressed together under $74,111,166$, and $333 \mathrm{MPa}$ in a polycarbonate tube (10 $\mathrm{mm}$ in diameter). Indium foil (thickness $=0.1 \mathrm{~mm}, \phi=$ $9 \mathrm{~mm}$ ) was used as the counter electrode and was attached on the solid electrolyte sides of the bilayer sheet. A pressure of $111 \mathrm{MPa}$ was applied to the three-layered sheet. Finally, the three-layered sheet was compressed at approximately $100 \mathrm{MPa}$ using two stainless-steel disks, which served as current collectors, and was held at this constant pressure throughout the cell testing.

Electrochemical tests were conducted in a constant current (CC) mode at a current density of $64 \mu \mathrm{A} \mathrm{cm}^{-2}$ (approximately
$0.05 \mathrm{C}$ rate) at room temperature using a charge-discharge measurement device (BTS-2004, Nagano). The cut-off voltages were 3.7 and $2.0 \mathrm{~V}$ vs $\mathrm{Li}-\mathrm{In}$, which correspond to 4.3 and $2.6 \mathrm{~V}$ vs Li. AC impedance measurements of the cells were performed after the initial charging to $3.7 \mathrm{~V}$ using an impedance analyzer (FRA1455, Solartron) in the frequency range of $0.1 \mathrm{~Hz}$ to $1 \mathrm{MHz}$ at room temperature.

The microstructure of the cross-sections of the composite electrode sheet was examined using scanning electron microscopy (SEM; JSM-6460LA, JSM-6610LA, JEOL). The cross-sectional samples were prepared from the composite positive electrode sheets by cutting with a razor blade, whereas those from the bilayer sheet were prepared using a dual-beam focused ion beam (FIB) (JSM-6460LA, JEOL).

\section{Results and discussion}

We investigated suitable solvents for the slurry with low vapor pressures that would not affect the conductivity of LPS glass. A Nyquist plot of the original LPS glass without mixing with the solvent only exhibits a straight line [Fig. 1(a)]. The intercept at the $X$-axis represents the resistance of LPS $\left(\mathrm{R}_{\mathrm{LPS}}\right)$, which can be converted into an ionic conductivity of $3.5 \times 10^{-4} \mathrm{~S} \mathrm{~cm}^{-1}$ at room temperature. After mixing the LPS with 1,4-dioxane [Fig. 1(b)] for one day, the Nyquist plot of the dried product comprised a semicircle corresponding to the interfacial resistance $\left(\mathrm{R}_{\mathrm{i}}\right)$. The total ionic conductivity, including $\mathrm{R}_{\mathrm{LPS}}$ and $\mathrm{R}_{\mathrm{i}}$, was $2.1 \times 10^{-5} \mathrm{~S} \mathrm{~cm}^{-1}$. The decrease in the conductivity was observed for the other solvents as well, for e.g., the conductivity decreased to $2.2 \times 10^{-6} \mathrm{~S} \mathrm{~cm}^{-1}$ when LPS was soaked in diethylene glycol dimethyl ether. In contrast, after mixing LPS with $n$ decane, the Nyquist plot of the dried product only showed a straight line [Fig. 1(c)], and the ionic conductivity was $3.2 \times$ $10^{-4} \mathrm{~S} \mathrm{~cm}^{-1}$. The conductivity in this case was kept almost the same as that for the original LPS. Similarly, the conductivities when 1,2-dichloroethane [Fig. 1(d)] and toluene were used as solvents were kept the same as that for the original LPS. The Nyquist plot of the dried product after dissolving $80 \mathrm{Li}_{2} \mathrm{~S} \cdot 20 \mathrm{P}_{2} \mathrm{~S}_{5}$ glass in N-methylformamide has been reported to contain a semicircle because the reprecipitation of dissolved glass can cause the formation of grain boundaries. ${ }^{18)}$ Therefore, the conductivity of the resulting product decreased by two orders of magnitude. ${ }^{18)}$ Considering that the Nyquist plots showed similar profiles for

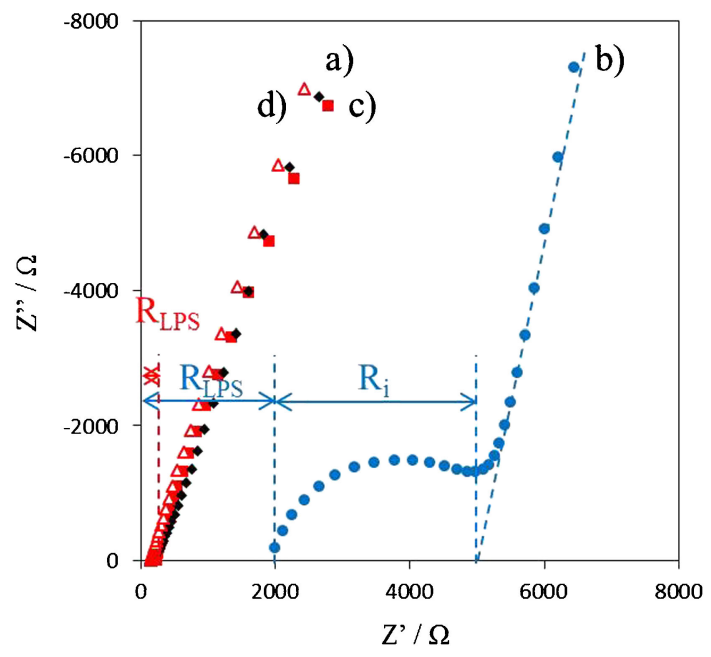

Fig. 1. Nyquist plots of a) original LPS and dried product after mixing with b) 1,4-dioxane, c) $n$-decane and d) 1,2-dichloroethane. 


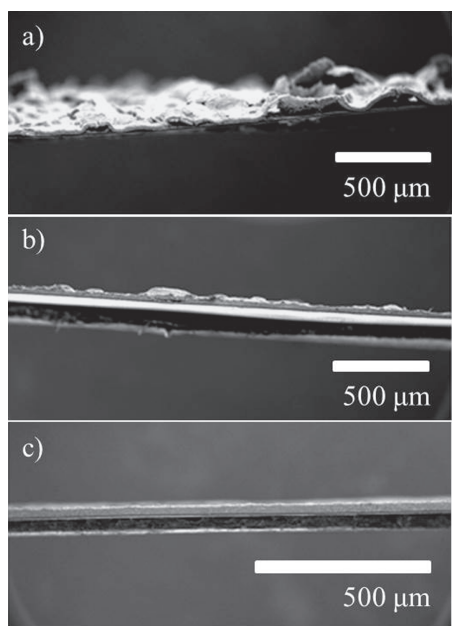

Fig. 2. Cross-sectional SEM images of the composite positive electrode sheets formed by coating the slurry using a) 1,2-dichloroethane, b) toluene, and c) n-decane.

diethylene glycol dimethyl ether and 1,4-dioxane [Fig. 1(b)], similar dissolution and reprecipitation may occur as follows; the LPS particles may partially dissolve in the nucleophilic solvent and then reprecipitate to form the grain boundaries. As the LPS hardly dissolved in non-nucleophilic solvents such as $n$-decane, 1,2-dichloroethane and toluene, the morphology and ionic conductivity should remain unchanged.

Figure 2 shows the cross-sectional SEM images of the composite positive electrode sheets formed by coating of the slurry using 1,2-dichloroethane, toluene, and $n$-decane. The sheet formed using 1,2-dichloroethane had a rough surface with some bulges and delaminated from the Aluminum (Al) film [Fig. 2(a)]. This behavior is caused by the rapid evaporation of 1,2dichloroethane with higher vapor pressure $(8.7 \mathrm{kPa}, 293 \mathrm{~K}) .{ }^{19)}$ For toluene with a lower vapor pressure $\left.(3.8 \mathrm{kPa}, 298 \mathrm{~K}),{ }^{19}\right)$ the obtained sheet was in contact with the Al film, and a slightly rough surface with aggregations was observed [Fig. 2(b)]. The sheet formed using $n$-decane, with the lowest vapor pressure $(0.17 \mathrm{kPa}, 298 \mathrm{~K}),{ }^{19)}$ had a dense and smooth surface without aggregations [Fig. 1(c)]. As a result, $n$-decane was selected as the solvent for the slurry in this study.

The distributions of NCM, LPS, and AB in the composite positive electrode sheets were characterized through SEM coupled with energy-dispersive X-ray spectroscopy (EDX) analysis. Figure 3(a) presents a cross-sectional SEM image of the fractured surface prepared by cutting the composite positive electrode sheet with a razor blade from top to bottom. Some delamination from the Al foil and cracking was transversely observed, which were formed when cutting the sample with the razor blade. The corresponding EDX mappings are presented in Figs. 3(b)-3(d). The $\mathrm{O}$ atoms of NCM particles, S atoms of LPS, and C atoms of acetylene black and SEBS were homogeneously dispersed from top to bottom of the composite positive electrode sheets. It is generally assumed that the heavier NCM particles tend to settle at the bottom and the lighter SE particles and acetylene black tend to float on the surface of the slurry; however, no obvious localization was observed in the overall sheet. Magnified SEM images and corresponding EDX mappings are presented in Figs. 3(e)-3(l). The $\mathrm{O}, \mathrm{Ni}, \mathrm{Co}$, and $\mathrm{Mn}$ atoms of $\mathrm{NCM}$ [Figs. 3(f), 3(i)-3(k)] were surrounded by $\mathrm{S}$ and $\mathrm{P}$ atoms of LPS [Figs. 3(g) and 3(l)]. In addition, no aggregation was observed for the $\mathrm{C}$ atoms of $\mathrm{AB}$ and SEBS [Fig. 3(h)]. Considering that the

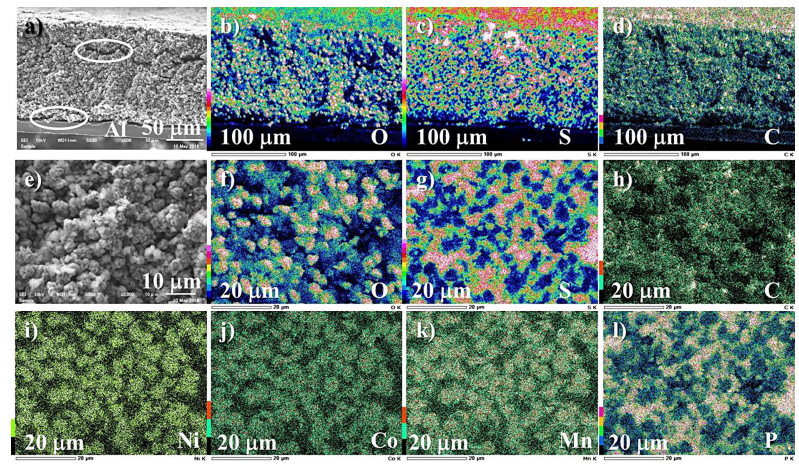

Fig. 3. a) SEM image and corresponding EDX mappings for b) $\mathrm{O}$, c) $\mathrm{S}$, and d) $\mathrm{C}$ of the cross-sectional fracture surface of composite positive electrode sheets prepared by coating the slurry using $n$-decane. The circles in a) indicate delamination from the Al foil and cracks. e) Magnified SEM image and corresponding EDX mappings for f) O, g) S, h) C, i) Ni, j) Co, k) Mn, and l) P.

$\mathrm{NCM}$ content was significantly higher $(80 \mathrm{wt} \%, 62 \mathrm{vol} \%)$ than that reported in previous reports on wet-mixing of $\mathrm{LiCoO}_{2}, \mathrm{Li}_{2} \mathrm{~S}-$ $\mathrm{P}_{2} \mathrm{~S}_{5}$ glass, and a conductive additive, with a weight ratio of $39: 59: 2,{ }^{20}$ the slurry in this study was successfully prepared with an excellent dispersion stability by controlling the solid component concentration and optimal mixing conditions using a planetary mixer and an ultrasonic homogenizer.

The densification of the composite positive electrode sheets was performed by compressing at 3,18, and $37 \mathrm{MPa}$ pressure at room temperature. The densities calculated from the thickness, diameter, and weight of the sheet were $1.12,2.41$, and $2.43 \mathrm{~g} \mathrm{~cm}^{-3}$, respectively. Compared with the theoretical density $\left(3.5 \mathrm{~g} \mathrm{~cm}^{-3}\right)$ calculated from the true density of NCM $\left(4.7 \mathrm{~g} \mathrm{~cm}^{-3}\right),{ }^{21)}$ LPS $\left(1.9 \mathrm{~g} \mathrm{~cm}^{-3}\right),{ }^{11)}$ SEBS $\left(0.9 \mathrm{~g} \mathrm{~cm}^{-3}\right)$ and AB $\left(2 \mathrm{~g} \mathrm{~cm}^{-3}\right)$ and their weight ratio, the obtained sheets exhibited considerably low densities. The sheet is considered to have some pores and voids because obvious grain boundaries and voids have been reported for compressed pellets, including $\mathrm{LiCoO}_{2}$ and $\mathrm{Li}_{2} \mathrm{~S}-\mathrm{P}_{2} \mathrm{~S}_{5}$ glass, at room temperature. ${ }^{22)}$ To evaluate the efficiency of the pre-pressing of the sheet, the electrochemical performance of the all-solid-state cells was investigated, and the results are presented in Fig. 4. Although large irreversible capacities were observed for all the cells during the initial cycle, the cells using the composite positive electrode sheets pressed at 18 and $37 \mathrm{MPa}$ exhibited larger discharge capacities of 126 and $125 \mathrm{mAh}^{-1}$, compared with that of the sheet pressed at $3 \mathrm{MPa}\left(111 \mathrm{mAh} \mathrm{g}^{-1}\right)$. In addition, the cell using the sheet pressed at $37 \mathrm{MPa}$ exhibited high discharge plateaus compared with those exhibited by the other cells. Thus, pre-densification of the composite positive electrode sheet at $37 \mathrm{MPa}$ was effective in forming an intimate contact between the NCM and LPS particles.

The effect of the fabrication pressure on the cell was investigated on the basis of the charge-discharge behavior and impedance spectra. First, the bilayer sheets composed of the pre-pressed composite positive electrode sheets (compressed at $37 \mathrm{MPa}$ ) and LPS powder were pressed at $74,111,166$, and $333 \mathrm{MPa}$. Then, the cells were fabricated by attaching indium foil to the bilayer sheet at $111 \mathrm{MPa}$. As observed in Fig. 5, the cells fabricated under lower pressure tended to exhibit higher first discharge capacities. Both cells fabricated at 111 and $74 \mathrm{MPa}$ exhibited initial discharge capacities in the range of $131-150 \mathrm{mAh} \mathrm{g}^{-1}$ with average discharge capacities of $137 \mathrm{mAhg}^{-1}$. In contrast, the 


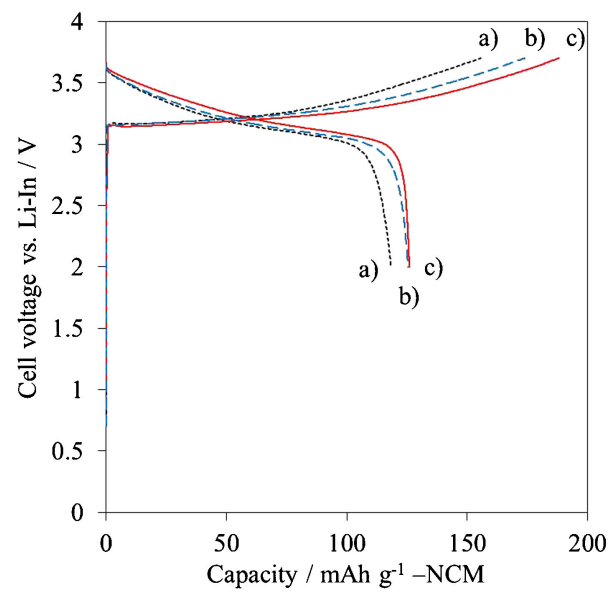

Fig. 4. Initial charge and discharge curves of the all-solid-state cells, In/LPS/composite electrode sheet $\left(\mathrm{LiNbO}_{3}\right.$ coated-NCM:LPS:AB: SEBS $=80: 20: 2: 1$ in weight ratio). The composite electrode sheets were compressed at a) 3, b) 18 , and c) $37 \mathrm{MPa}$, and the bilayer sheets consisting of the composite electrode sheets and LPS powder were then compressed at $333 \mathrm{MPa}$. Charge and discharge measurements were performed under a constant current density of $64 \mu \mathrm{A} \mathrm{cm}^{-2}$ at room temperature.

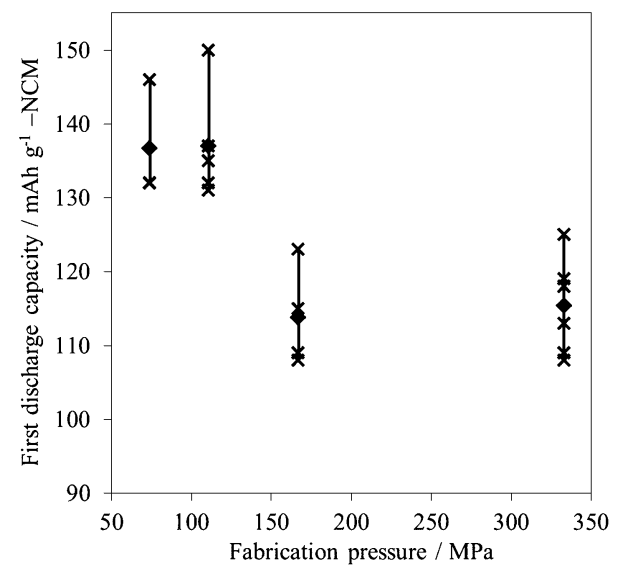

Fig. 5. Initial discharge capacities of the all-solid-state cells, In/ LPS/composite electrode sheet $\left(\mathrm{LiNbO}_{3}\right.$ coated-NCM:LPS:AB:SEBS $=$ 80:20:2:1 in weight ratio). The composite electrode sheets were pressed at $37 \mathrm{MPa}$, and the bilayer sheets consisting of the composite electrode sheet and LPS powder were then pressed at 74, 111, 166, and $333 \mathrm{MPa}$. The cross marks and diamonds indicate the discharge capacity of the individual cell and average discharge capacity, respectively.

cells fabricated at 333 and $166 \mathrm{MPa}$ exhibited lower initial discharge capacities in the range of $108-125 \mathrm{mAh} \mathrm{g}^{-1}$ with average discharge capacities of 115 and $114 \mathrm{mAh} \mathrm{g}^{-1}$, respectively.

To reveal the relation between the fabrication pressure and cell internal resistance, impedance spectra were measured for the representative cells fabricated at $74,111,166$, and $333 \mathrm{MPa}$ pressure after charging to $3.7 \mathrm{~V}$ at a current density of $64 \mu \mathrm{A} \mathrm{cm}^{-2}$. The impedance spectra of the cells and corresponding initial charge and discharge curves are presented in Fig. 6. The identification of the impedance components has been reported earlier. ${ }^{23)}$ The resistance observed in the higher frequency region $(>10 \mathrm{kHz})$ corresponds to the resistance of the solid electrolyte $\left(\mathrm{R}_{\mathrm{LPS}}\right)$. The semicircle observed in the medium frequency $(10 \mathrm{kHz}-100 \mathrm{~Hz})$ with a peak top frequency of $1 \mathrm{kHz}$ is considered as the interfacial resistance between NCM and LPS in positive electrode layer $\left(\mathrm{R}_{\mathrm{PE}}\right)$. The semicircle observed in the lower frequency range (10-
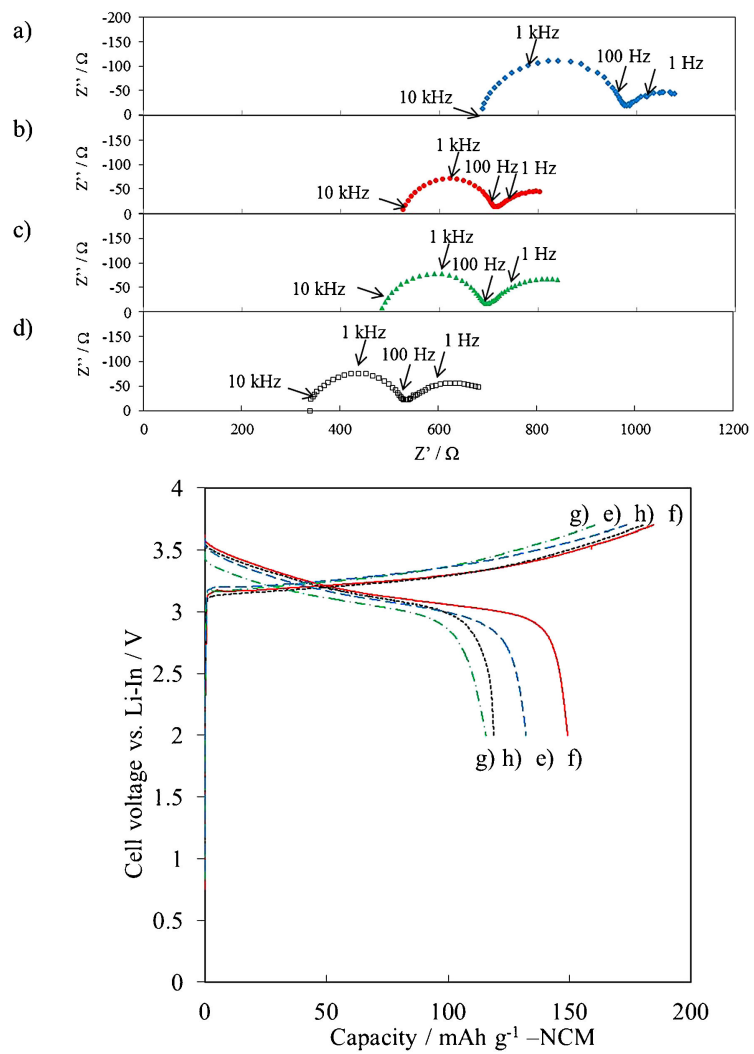

Fig. 6. a-d) Nyquist plots after initial charging to $3.7 \mathrm{~V}$ and $\mathrm{e}-\mathrm{h}$ ) corresponding initial charge and discharge curves of the cells fabricated at pressures of a, e) 74, b, f) 111, c, g) 166, and d, h) $333 \mathrm{MPa}$.

$0.1 \mathrm{~Hz}$ ) with a peak top frequency of $1 \mathrm{~Hz}$ is the resistance in the negative electrode $\left(\mathrm{R}_{\mathrm{NE}}\right)$. As observed in Figs. 6(a)-6(d), the resistance of the solid electrolyte, $R_{\text {LPS }}$, drastically decreases from 683 to $341 \Omega$ with increasing fabrication pressure from 74 to $333 \mathrm{MPa}$. This result is reasonable because a highly dense LPS glass pellet with low resistance tends to be formed under high pressure through the deformation among LPS particles to create intimate contacts. ${ }^{7), 11)}$ The interfacial resistances between NCM and the solid electrolyte, $\mathrm{R}_{\mathrm{PE}}$, are hard to compare simply because $\mathrm{R}_{\mathrm{PE}}$ is affected by the loading of NCM and the contact area between NCM and LPS. Furthermore, the cell voltages after charging were slightly different in each cell. The cells fabricated at different pressure exhibit almost similar $\mathrm{R}_{\mathrm{PE}}$ in the range of $180-280 \Omega$. Remarkable tendency was not observed in $R_{P E}$ by the fabrication pressure. The resistances in the negative electrode, $\mathrm{R}_{\mathrm{NE}}$, were similar around $220 \Omega$, because the indium foil was attached to the bilayer pellet at the same pressure in the final fabrication process. As a result, the difference of the total cell internal resistance including $R_{L P S}, R_{P E}$ and $R_{N E}$ is mainly derived from $R_{L P S}$, which decreases with increasing fabrication pressure. In general, a cell with lower internal resistance exhibits higher performance; however, in this case, the cells fabricated at lower pressure, such as 111 and $74 \mathrm{MPa}$, exhibited higher initial discharge capacities [Figs. 6(e) and 6(f)] despite the higher internal resistance.

To understand these anomalous results, the microstructures of the bilayer sheets fabricated at $111 \mathrm{MPa}$ [Fig. 7(a)] and $333 \mathrm{MPa}$ [Fig. 7(b)] were compared by FIB-SEM observation. The sheet pressed at $111 \mathrm{MPa}$ consisted of loosely packed layer with some large voids, indicated by circles in Fig. 7(a). In addition, LPS present between the NCM particles, as indicated by the arrows in 


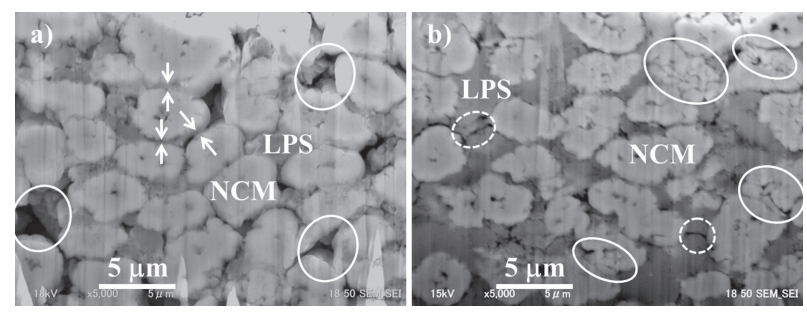

Fig. 7. Cross-sectional FIB-SEM images of bilayer sheets prepared by pressing the pre-pressed composite electrode sheet $\left(\mathrm{LiNbO}_{3}\right.$ coatedNCM:LPS:AB:SEBS $=80: 20: 2: 1 \mathrm{wt} \%$, NCM:LPS $=62: 38 \mathrm{vol} \%$ ) at 37 $\mathrm{MPa}$ and LPS powder at a) $111 \mathrm{MPa}$ and b) $333 \mathrm{MPa}$. The circles and arrows in a) indicate voids and LPS sandwiched by NCM, respectively. The circles and dotted circles in $b$ ) indicate the noticeable pulverization of NCM and cracking of LPS, respectively.

Fig. 7(a). In contrast, the sheet pressed at $333 \mathrm{MPa}$ was relatively densely packed; pulverizing and fracturing of the NCM particles and cracks in the LPS were observed, as indicated by the solid and dotted circles in Fig. 7(b), respectively. LPS can deform without fracturing on applying mechanical stress, ${ }^{7), 15)}$ whereas the metal oxide, NCM, is relatively hard and brittle. Therefore, the plastic deformation of LPS particles occurs by compression with NCM particles, which contributes to the generation of an intimate contact between NCM and LPS and suppresses the fracturing of NCM. However, when the fabrication pressure is too high, closely located NCM particles push LPS aside and contact each other directly, resulting in the fracturing of NCM particles.

These phenomena should be strongly related to the difference of the charge-discharge capacities. The fracturing of NCM particles decreases the utilization ratio of NCM due to the generation of electronically and ionically isolated NCM and also the decrease of the lithium-ion conductivity in the positive electrode, which decrease rate capability. The influence of the fracturing of NCM particles on $R_{P E}$ is relatively small compared with that on charge-discharge capacities in this study. The reason why the influence of the fracturing is not clearly observed in the Nyquist plots would be that the ratio of the fractured NCM particles is relatively small compared with that of the non-fractured particles. In addition, many parameters such as the bulk properties of $\mathrm{NCM}$, loading of the composite electrode, contact area of NCM/ LPS, lithium-ion and electron conductivities of positive electrode layer and binder directly affect $\mathrm{R}_{\mathrm{PE}}$.

Our results show that the careful optimization of the fabrication pressure is critical, especially for the usage of composite positive electrode sheets with high NCM content.

\section{Conclusions}

We have systematically investigated the fabrication of allsolid-state batteries using a composite positive electrode sheet with high NCM content. Although the solvents available for the slurry are limited to non-nucleophilic solvents, a smooth and flat electrode sheet was successfully prepared using $n$-decane with low vapor pressure. To the best of our knowledge, this study is the first to report an electrode with high NCM content $(80 \mathrm{wt} \%$ of the total electrode) fabricated using the slurry coating method. Pre-compression of the positive electrode sheet was effective in densifying the composite electrode sheet and improving the cell performance. We further revealed that a high fabrication pressure induced pulverization and cracking of NCM and cracking of LPS in the positive composite electrode, resulting in a decrease of the discharge capacity. This study provides valuable information about the design of an electrode sheet with high active material content and about suitable fabrication pressures for sheet-type batteries using laminating electrode sheets and solid electrolyte sheets.

Acknowledgements This research was financially supported by the Japan Science and Technology Agency (JST), Advanced Low Carbon Technology Research and Development Program, Specially Promoted Research for Innovative Next Generation Batteries (ALCA-SPRING) Project.

\section{References}

1) K. Takada, Acta Mater., 61, 759-770 (2013).

2) S. D. Jones and J. R. Akridge, Solid State Ionics, 86-88, 12911294 (1996).

3) R. Kanno and M. Murayama, J. Electrochem. Soc., 148, A742-A746 (2001).

4) S. Hama, M. Morimoto, M. Tatsumisago and T. Minami, J. Am. Ceram. Soc., 84, 477-479 (2001).

5) A. Hayashi, S. Hama, T. Minami and M. Tatsumisago, Electrochem. Commun., 5, 111-114 (2003).

6) F. Mizuno, A. Hayashi, K. Tadanaga and M. Tatsumisago, $A d v$. Mater., 17, 918-921 (2005).

7) A. Sakuda, A. Hayashi and M. Tatsumisago, Sci. Rep., 3, 2261 (2013).

8) F. Mizuno, A. Hayashi, K. Tadanaga and M. Tatsumisago, Solid State Ionics, 177, 2731-2735 (2006).

9) A. Hayashi, S. Hama, F. Mizuno, K. Tadanaga, T. Minami and M. Tatsumisago, Solid State Ionics, 175, 683-686 (2004).

10) T. Minami, A. Hayashi and M. Tatsumisago, Solid State Ionics, 177, 2715-2720 (2006).

11) A. Sakuda, A. Hayashi, Y. Takigawa, K. Higashi and M. Tatsumisago, J. Ceram. Soc. Japan, 121, 946-949 (2013).

12) T. Inada, T. Kobayashi, N. Sonoyama, A. Yamada, S. Kondo, M. Nagao and R. Kanno, J. Power Sources, 194, 1085-1088 (2009).

13) Y. J. Nam, S.-J. Cho, D. Y. Oh, J.-M. Lim, S. Y. Kim, J. H. Song, Y.-G. Lee, S.-Y. Lee and Y. S. Jung, Nano Lett., 15, 3317-3323 (2015).

14) K. Sugiura and M. Ohashi, WO patent WO2013/073035.

15) A. Sakuda, T. Takeuchi and H. Kobayashi, Solid State Ionics, 285, 112-117 (2016).

16) N. Ohta, K. Takada, I. Sakaguchi, L. Zhang, R. Ma, K. Fukuda, M. Osada and T. Sasaki, Electrochem. Commun., 9, 1486-1490 (2007).

17) A. Sakuda, H. Kitaura, A. Hayashi, K. Tadanaga and M. Tatsumisago, J. Electrochem. Soc., 156, A27-A32 (2009).

18) S. Teragawa, K. Aso, K. Tadanaga, A. Hayashi and M. Tatsumisago, Chem. Lett., 42, 1435-1437 (2013).

19) International Chemical Society Cards (ICSC): $n$-decane 0428 , toluene 0078, 1,2-dichloroethane 0250, Diethylene glycol dimethyl ether 1357, 1,4-dioxane 0041.

20) J. Kim, M. Eomb, S. Noh and D. Shin, J. Power Sources, 244, 476-481 (2013).

21) M. Yoshio and H. Noguchi, Lithium-Ion Batteries, Ed. by M. Yoshio, R. J. Brodd and A. Kozawa, Springer, New York (2009) pp. 9-48.

22) H. Kitaura, A. Hayashi, T. Ohtomo, S. Hama and M. Tatsumisago, J. Mater. Chem., 21, 118-124 (2011).

23) A. Sakuda, H. Kitaura, A. Hayashi, K. Tadanaga and M. Tatsumisago, J. Electrochem. Soc., 156, A27-A32 (2009). 